\title{
Are meat options preferred to comparable vegetarian options? An experimental study
}

\author{
Rachel Pechey ${ }^{1,2^{*}} \mathbb{D}$, Gareth J. Hollands ${ }^{1}$ and Theresa M. Marteau ${ }^{1}$
}

\begin{abstract}
Objective: Reducing meat consumption would have substantial benefits both in terms of health and environmental impact, but meat options may be more attractive to customers than meat-free options. This study tested this by presenting UK adults $(n=540)$ with a series of pictures showing two meal options and asking them to select which they would prefer to eat right now. They completed this task for every possible pair from a pool of six comparator meat-based options and six target options (66 pairs). Participants all saw identical comparator options, and were randomised to see the same pictures of target options but with descriptions that suggested they were either meatbased or vegetarian.

Results: Selections were used to rank the options for each individual from 1 (most-selected) to 12 (least-selected). Vegetarian target options were ranked worse [by 1.23 places ( $95 \%$ Cl: 1.02, 1.44)] than meat target options. Higher selfreported consumption of meat predicted worse mean rankings of target options when these were vegetarian, but not when target options were meat-based. This suggests meat options are preferred to equivalent vegetarian options and may be more likely to be selected. This has implications for interventions aiming to reduce meat consumption to make diets healthier and more sustainable.
\end{abstract}

Keywords: Meat, Vegetarian, Preferences, Food, Sustainability, Health

\section{Introduction}

Reducing meat consumption could lead to substantial benefits both in terms of health and environmental impact [1]. However, one barrier to changing meat consumption may be societal and individual preferences for eating meat-with meat consumption described as being natural, normal, necessary and nice [2]. Preferences for meat may play a substantial role in determining food selection and consumption, with the most common reason given for eating meat in a large Belgian survey being taste [3]. This reflects reported barriers to reducing meat consumption including enjoying meat and family food preferences [4]. Moreover, those with stronger preferences for meat may be most resistant to changing their

\footnotetext{
*Correspondence: Rachel.pechey@phc.ox.ac.uk

${ }^{1}$ Behaviour and Health Research Unit, Institute of Public Health,

University of Cambridge, Cambridge, UK

Full list of author information is available at the end of the article
}

behaviour [5]. In contrast, meat substitutes may have limited acceptance given their unfamiliarity and perceived lower sensory attractiveness [6].

Given the significance placed on preferences in selfreported motivations for selecting foods that contain meat, the current study aimed to experimentally examine the extent to which preferences differ depending on whether the available options are meat-based or vegetarian. In particular, in order to try to isolate differences due to the presence or absence of meat, the study compared responses to the same picture of a meal, which was described as either a vegetarian option or an equivalent option containing meat. This tightly-controlled study allows an exploration of the extent to which the meat component drives preferences, independent of the meal type and the visual attractiveness of the meal.

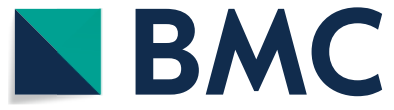

(c) The Author(s) 2021. This article is licensed under a Creative Commons Attribution 4.0 International License, which permits use, sharing, adaptation, distribution and reproduction in any medium or format, as long as you give appropriate credit to the original author(s) and the source, provide a link to the Creative Commons licence, and indicate if changes were made. The images or other third party material in this article are included in the article's Creative Commons licence, unless indicated otherwise in a credit line to the material. If material is not included in the article's Creative Commons licence and your intended use is not permitted by statutory regulation or exceeds the permitted use, you will need to obtain permission directly from the copyright holder. To view a copy of this licence, visit http://creativeco mmons.org/licenses/by/4.0/. The Creative Commons Public Domain Dedication waiver (http://creativecommons.org/publicdomain/ zero/1.0/) applies to the data made available in this article, unless otherwise stated in a credit line to the data. 
Table 1 Mean (s.d.) rankings by selection for each food option, by study condition, with higher values indicating lessselected options

\begin{tabular}{llll}
\hline & & Meat condition & Vegetarian condition \\
\hline Comparator & Lasagne (beef) & $4.5(3.2)$ & $3.8(3.0)$ \\
& Battered fish & $4.7(3.7)$ & $3.9(3.2)$ \\
& Beef pie & $5.3(3.3)$ & $5.3(3.1)$ \\
& Arrabbiata with meatballs & $6.4(3.3)$ & $5.6(3.0)$ \\
& BBQ Chicken & $6.8(3.3)$ & $6.0(2.9)$ \\
& Chicken Milanese & $7.0(3.0)$ & $5.0(1.3)$ \\
Target & Mean & $7.6(3.0)$ & $7.2(3.2)$ \\
& Cottage pie (beef/soya) & $6.2(1.1)$ & $7.9(3.1)$ \\
& Fajita (chicken/vegetable) & $5.4(3.5)$ & $7.8(2.8)$ \\
& Balti (chicken/vegetable) & $5.9(3.6)$ & $9.6(2.8)$ \\
& Black bean (chicken/tofu) & $6.9(3.2)$ & $7.7(2.5)$ \\
& Cajun (beef/vegetable) & $7.2(3.2)$ & $7.8(2.8)$ \\
& Chilli (turkey/soya) & $7.6(2.8)$ & $8.0(1.3)$ \\
\hline
\end{tabular}

N.B. Rankings for individual options go from 1 (most-selected from paired-selections) to 12 (least-selected). Mean rankings for the target and comparator categories are bounded at 3.5 (all six options belonging to that category are ranked 1-6-the top six places) and 9.5 (all six options belonging to that category are ranked 7-12-the bottom six places)

\section{Main text \\ Methods \\ Participants}

A sample of 540 UK adults was recruited from existing members of a market research agency panel (Dynata), Participants were invited to participate via email sent by Dynata, or links placed on their website. Quotas were set to obtain equal numbers by highest educational qualification (lower: Up to GCSE level or 1 A level; higher: $2+$ A levels or equivalent, or higher qualification), and to ensure a representative sample by age and gender. Participants with dietary restrictions (e.g., vegetarians) were excluded, to ensure that participants could select any of the options offered. Quality checks included excluding participants who failed attention check questions $(\mathrm{n}=87)$ or completed the study in $<30 \%$ of the median time $(\mathrm{n}=1)$.

The sample size was based on a t-test to find an effect size of $d=0.28$ (equivalent to the difference in preference rankings between lower energy and higher energy main meals in a previous study, due to there being no direct evidence and lower energy options in this previous study including more vegetarian options [7]), with alpha $=0.05$, and power of 0.9 . The sample size required was calculated using $\mathrm{G}^{*}$ Power 3.1.9.2 to be 270 per group, so 540 in total.

\section{Design}

This was an online study, with one between-subjects factor (meat vs. vegetarian options).
The study was pre-registered on the Open Science Framework (https://osf.io/yjmpe) and ISRCTN (http:// www.isrctn.com/ISRCTN15043170). Ethical approval was obtained from the University of Cambridge Psychology Research Ethics Committee (Ref: Pre.2020.030).

A second aim of this study was to act as a pilot study to identify options to be used in a subsequent study-this aim has been written up elsewhere [7].

\section{Materials}

Six comparator and six target main meal options were identified from the manual used in a previous study [7]. Due to the second aim of this study (acting as a pilot for a subsequent study), comparator meal options were all higher energy, while target options were lower energy (defined as those with under $500 \mathrm{kcal}$ for a complete meal, whereas higher energy had $500 \mathrm{kcal}$ or more [8]).

All the comparator meal options were meat-based (see Table 1 for the list of options). Meat and vegetarian versions were created for target meal options, which were described under the same dish name, aside from the meat vs. vegetarian content (e.g., vegetable Balti vs. chicken Balti). The same photograph was used for both the meat and vegetarian versions of the target options, with the dish name displayed underneath.

\section{Procedure}

Each participant was randomised to see target options that were labelled as either meat-based or vegetarian options. Participants all saw the same six comparator meal options, which were all meat-based. 
Participants were presented with pictures of two food options, and asked to select which they would prefer to eat right now. They completed this task for every possible item pair for the comparator main meal options and their assigned target options (66 item pairs).

Participants then completed measures of age, gender, highest educational qualification, household income, usual meat consumption ("How often do you usually eat meat?" 6 options from 'Less than once a week' to 'More than twice a day') and hunger (7 point rating scale, from 'Very hungry' to 'Very full').

\section{Analyses}

The primary outcome was the mean ranking for target options, based on the number of times it was selected. For each trial, the selected item received a score of 1 . Scores were summed across all trials for each item for each participant. Rankings for the meal options were created for each participant, from 1 (most-selected from paired-selections) to 12 (least-selected). For ties in relative rankings both tied items' rankings were recorded as 1.5, 2.5 or 3.5 (i.e. tied for first, second or third place, respectively). As such, higher rankings indicate options that are less-selected, implying these are less-preferred.

The primary analysis was a multiple regression predicting the rankings for target meals depending on whether these options were vegetarian or meat-based (with the reference group coded as the meat-based target options). Age, gender, education and hunger were included as covariates.

Usual meat consumption, and its interactions with meal meat content, were then added to the above model to examine whether any difference in rankings for meatbased vs. vegetarian target options was moderated by usual meat consumption.

\section{Results}

Of the 540 participants, $51.3 \%$ were female $(n=277)$. The mean age was 46.9 (s.d. 16.8; range 18-79), and 50\% had lower education $(n=270)$. The majority were white (92.6\%, $\mathrm{n}=497 ; 7.3 \%$ other, $\mathrm{n}=38 ; 0.9 \%$ missing, $\mathrm{n}=5$ ), and the mean hunger rating was 0.60 (s.d. 1.38). In terms of usual meat consumption, $30.7 \%(n=116)$ reported eating meat 3 times per week or less, $47.0 \%(n=254) 4-6$ times per week and $22.2 \%(n=120)$ daily.

The distribution of participants between the meat vs. vegetarian conditions was not exactly equal, due to exclusions occurring after randomisation for speeding or failing attention checks, with 275 participants in the vegetarian condition (50.9\%) and 265 in the meat condition (49.1\%).

\section{Primary analysis}

In terms of selections, target options were selected on average 31.1 times (s.d. 6.3) in the meat condition and 24.2 times (s.d. 7.3) in the vegetarian condition (means for comparator options being 34.9 times and 41.8 times, respectively).

Preferences were examined by looking at the mean rankings by selection for target and comparator options (see Table 1), with comparator options tending to be more selected but this distinction being greater in the vegetarian target options condition than the meat target options condition (mean of 6.2 for comparator options vs. 6.8 for target options in the meat condition; 5.0 vs. 8.0 in the vegetarian condition).

Examination of the data revealed that a number of data points for vegetarian options were at the maximum score (i.e., consistently avoided $)(\mathrm{n}=36)$. Therefore a Tobit regression model was used. The model suggested a coefficient of 1.23 (95\% CI: 1.02, 1.44; $\mathrm{p}<0.001$ ) for vegetarian (rather than meat) options (controlling for age, gender, education and hunger) (see Additional file 1: Table S1 for full model results). This suggests mean rankings for vegetarian options were 1.23 units higher than mean rankings for meat options-equivalent to each vegetarian option being ranked one place worse on average than the equivalent meat options.

\section{Interactions by usual meat consumption}

Usual meat consumption and interactions between the meat vs. vegetarian condition and usual meat consumption were added into the regression model. These additions reduced the coefficient for the vegetarian condition to 0.69 (95\%CIs: $0.32,1.05)$-now equivalent to the difference between conditions for those who reported eating meat 3 times a week or less. There were no significant

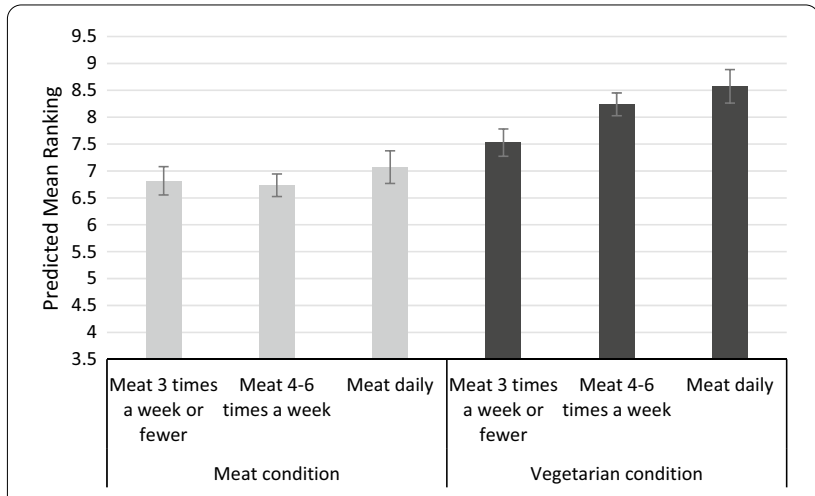

Fig. 1 Predicted mean rankings of target options for meat vs. vegetarian target options by usual meat consumption. N.B. Error bars represent $95 \% \mathrm{Cl}$ s. Scores are based on mean ranking of items, so higher scores reflect less-selected items 
main effects of usual meat consumption (coefficient for meat 4-6 times per week: $-0.1,95 \%$ CIs: $-0.4,0.3$; coefficient for meat daily: 0.3, 95\%CIs: $-0.1,0.7)$. Figure 1 shows how higher reported consumption of meat predicted worse mean rankings in the vegetarian, but not in the meat condition (interaction coefficient for meat 4-6 times per week $\times$ vegetarian: $0.8,95 \%$ CIs: $0.3,1.3$; interaction coefficient for meat daily $\times$ vegetarian: 0.8 , $95 \%$ CIs: 0.2, 1.4) (see Additional file 1: Table S2 for full model results).

\section{Discussion}

The results of this study suggest that meat meal options are selected more often than vegetarian options even when visual attractiveness and meal type are held constant. For meat-based target options, there was overlap between the rankings for these options and comparator options. In contrast, no vegetarian option was better ranked than any of the comparator options. Meat options were increasingly selected with increasing frequency of usual meat consumption. This may reflect previous work suggesting that there may be a group of individuals characterised by high preferences for meat and who are less open to reducing their meat consumption [5].

Given the role preferences may play in guiding food selections, this pattern of results raises some concern in that preferences for meat over vegetarian options could limit the effectiveness of attempts to reduce meat consumption in our diets. Stronger interventions may be needed to counteract the impact of preferences, or interventions that could mitigate against this effect could be prioritised. For example, meat-based options were by no means always selected over vegetarian ones, and with an increased number of vegetarian options (and reduced number of meat-based options), the chances of their being a preferable vegetarian option should increaseand lead to increase selections of vegetarian options, as found in one field study [9].

In conclusion, this study suggested meat options were preferred to equivalent vegetarian options. This highlights some of the difficulties faced in aiming to make diets healthier and more sustainable by reducing meat consumption.

\section{Limitations}

This was a relatively small study, examining a limited number of main meal options, and conducted online so that participants only had visual cues and did not receive any of the meals they selected. Nevertheless, it offers an initial exploration of the differences in preferences between vegetarian and main meals in a controlled setting, using a sample of photographs taken from cafeterias. Further research can explore a greater range of options-including whether there are differences in preferences depending on the kinds of vegetarian options available-e.g., with the primary component being vegetables, cheese, or meat substitutes, or comparing higher energy meat vs. vegetarian options. These are likely to be subject to different barriers to acceptance, e.g. meat substitutes may be subject to greater neophobia. This research could help to establish how best to implement interventions to try to reduce meat consumption-for example, by guiding implementers towards kinds of vegetarian options that might be best accepted-albeit with the health and environmental benefits of these alternatives also varying. In addition, further work could explore different ways of presenting vegetarian options to make them more attractive-for example, taking advantage of their natural colourfulness [10].

\section{Supplementary Information}

The online version contains supplementary material available at https://doi. org/10.1186/s13104-021-05451-9.

Additional file 1: Table S1 Tobit regression model predicting the mean ranking score for target options. Table S2 Tobit regression model predicting the mean ranking score for target options, with interactions by usual meat consumption

\section{Abbreviation}

GCSE: General Certificate of Secondary Education.

\section{Acknowledgements}

Not applicable.

Authors' contributions

RP, GJH and TMM designed the study. RP analysed the data and drafted the manuscript. GJH and TMM provided critical revisions to the manuscript. All authors read and approved the final manuscript.

Funding

RP is supported by a Wellcome Trust Research Fellowship in Society and Ethics [106679/Z/14/Z]. TMM and GJH hold a Collaborative Award in Science from Wellcome Trust (Behaviour Change by Design: 206853/Z/17/Z to Theresa Marteau, Paul Fletcher, Gareth Hollands and Marcus Munafò). The funders had no role in the study design, data collection, analysis, or interpretation.

\section{Availability of data and materials}

The dataset generated during the current study are available in the Open Science Framework https://osf.io/hcxz3/.

\section{Ethics approval and consent to participate}

Ethical approval was obtained from the Cambridge Psychology Research Ethics Committee (PRE.2020.030). Written consent was obtained from all participants.

\section{Consent for publication}

Not applicable.

Competing interests

None. 


\section{Author details}

1 Behaviour and Health Research Unit, Institute of Public Health, University of Cambridge, Cambridge, UK. ${ }^{2}$ Nuffield Department of Primary Care Health Sciences, University of Oxford, Oxford OX2 6GG, UK.

Received: 13 November 2020 Accepted: 12 January 2021

Published online: 26 January 2021

\section{References}

1. Springmann M, Wiebe K, Mason-D'Croz D, Sulser TB, Rayner M, Scarborough $\mathrm{P}$. Health and nutritional aspects of sustainable diet strategies and their association with environmental impacts: a global modelling analysis with country-level detail. The Lancet Planetary Health. 2018;2(10):e451-61.

2. Piazza J, Ruby MB, Loughnan S, Luong M, Kulik J, Watkins HM, et al. Rationalizing meat consumption. The 4Ns. Appetite. 2015;91:114-28.

3. Mullee A, Vermeire L, Vanaelst B, Mullie P, Deriemaeker P, Leenaert T, et al. Vegetarianism and meat consumption: a comparison of attitudes and beliefs between vegetarian, semi-vegetarian, and omnivorous subjects in Belgium. Appetite. 2017:114:299-305.

4. Lea E, Worsley A. Benefits and barriers to the consumption of a vegetarian diet in Australia. Public Health Nutr. 2003;6(5):505-11.
5. Graça J, Oliveira A, Calheiros MM. Meat, beyond the plate. Data-driven hypotheses for understanding consumer willingness to adopt a more plant-based diet. Appetite. 2015;90:80-90.

6. Hoek AC, Luning PA, Weijzen P, Engels W, Kok FJ, de Graaf C. Replacement of meat by meat substitutes. A survey on person- and product-related factors in consumer acceptance. Appetite. 2011;56(3):662-73.

7. Pechey R, Hollands GJ, Marteau TM. Explaining the effect on food selection of altering availability: two experimental studies on the role of prior preferences. https://doi.org/10.31234/osf.io/fkqvh (in submission)

8. Pechey R, Cartwright E, Pilling M, Hollands GJ, Vasiljevic M, Jebb SA, et al. Impact of increasing the proportion of healthier foods available on energy purchased in worksite cafeterias: a stepped wedge randomised controlled pilot trial. Appetite. 2019;133:286-96.

9. Garnett EE, Balmford AP, Sandbrook C, Pilling MA, Marteau TM. Impact of increasing vegetarian availability on meal selection and sales in cafeterias. PNAS. 2019;116:20923.

10. König LM, Renner B. Boosting healthy food choices by meal colour variety: results from two experiments and a just-in-time Ecological Momentary Intervention. BMC Public Health. 2019;19(1):975.

\section{Publisher's Note}

Springer Nature remains neutral with regard to jurisdictional claims in published maps and institutional affiliations.
Ready to submit your research? Choose BMC and benefit from:

- fast, convenient online submission

- thorough peer review by experienced researchers in your field

- rapid publication on acceptance

- support for research data, including large and complex data types

- gold Open Access which fosters wider collaboration and increased citations

- maximum visibility for your research: over $100 \mathrm{M}$ website views per year

At BMC, research is always in progress.

Learn more biomedcentral.com/submissions 